\title{
Arrhythmia in thiamine responsive megaloblastic anemia syndrome
}

\author{
Mustafa Argun ${ }^{1}$, Ali Baykan², Nihal Hatipoğlu³, Leyla Akın³ ${ }^{3}$ Yavuz Şahin ${ }^{4}$, Nazmi Narin², \\ Selim Kurtoğlu ${ }^{3}$ \\ ${ }^{1}$ Department of Pediatrics, Division of Pediatric Cardiology, Health Sciences University; ${ }^{2}$ Department of Pediatric Cardiology, \\ Erciyes University Medical Faculty; ${ }^{3}$ Department of Pediatric Endocrinology, Erciyes University Medical Faculty, Kayseri; \\ ${ }^{4}$ Medical Genetic Clinic, Necip Fazll City Hospital, Kahramanmaraş, Turkey. \\ E-mail:drmargun@gmail.com
}

Received: 14th August 2017, Revised: 20th September 2017, Accepted: 30th November 2017

SUMMARY: Argun M, Baykan A, Hatipoğlu N, Akın L, Şahin Y, Narin N, Kurtoğlu S. Arrhythmia in thiamine responsive megaloblastic anemia syndrome. Turk J Pediatr 2018; 60: 348-351.

Thiamine responsive megaloblastic anemia syndrome (TRMAS) is a rare, autosomal recessive disorder characterized by megaloblastic anemia, diabetes mellitus, and progressive sensorineural deafness. Mutations in the SLC19A2 gene that codes for thiamine transporter 1 protein cause TRMAS, and more than 30 homozygous mutations have been identified to date. Congenital heart diseases and arrhythmias have been reported in few patients. We present cardiac features of five patients with TRMAS. Five patients had macrocytic anemia, diabetes mellitus, and sensorineural deafness. Two siblings had also optic atrophy. SLC19A2 gene mutation was shown in all patients. Two patients developed supraventricular tachycardia during an episode of diabetic ketoacidosis. Five patients had absent $\mathrm{P}$ waves on baseline electrocardiography, and one patient had additional low QRS voltage. None of the patients had structural heart disease. Discontinuation of thiamine treatment appears to trigger supraventricular tachycardia episodes at puberty.

Key words: arrhythmia, thiamine, deafness, diabetes mellitus, megaloblastic anemia.

Thiamine responsive megaloblastic anemia syndrome (TRMAS) is a rare, autosomal recessive disorder characterized by megaloblastic anemia, diabetes mellitus, and progressive sensorineural deafness. ${ }^{1}$ In addition, optic nerve abnormalities, congenital heart diseases, and arrhythmias have been reported in some patients. Thiamine is a cofactor of pyruvate dehydrogenase, alpha ketoglutarate dehydrogenase, and transketolase enzymes, which play an important role in energy metabolism (Fig. 1). Intracellular thiamine deficiency impairs aerobic oxidative synthesis of ATP and DNA/RNA biosynthesis, leads to cellular death and apoptosis. Thiamine enters cell via thiamine transporter 1 and/ or thiamine transporter 2.1,2 Mutations in the SLC19A2 gene that codes for thiamine transporter 1 cause TRMAS, and more than 30 homozygous mutations have been identified to date. ${ }^{2}$ Thiamine transporter 1 is the dominant transporter in inner ear cells, pancreatic islet cells, and hematopoietic stem cells. ${ }^{1,2}$

Macrocytic anemia responds very well to thiamine. Diabetes also responds very favorably to thiamine treatment initially, so that glucose levels revert to normal without the need of insulin therapy. However, patients exhibit diminished response to thiamine and become insulin-dependent despite taking a sufficient amount of thiamine with the onset of puberty. Unfortunately, thiamine does not provide much benefit for preventing deafness. ${ }^{3}$

We present five TRMAS cases (female/male; $3 / 2$ ), four of which we had previously reported as general clinic. ${ }^{3-6}$ The youngest and the oldest patients were four months and five years old, respectively at the time of diagnosis. Case 


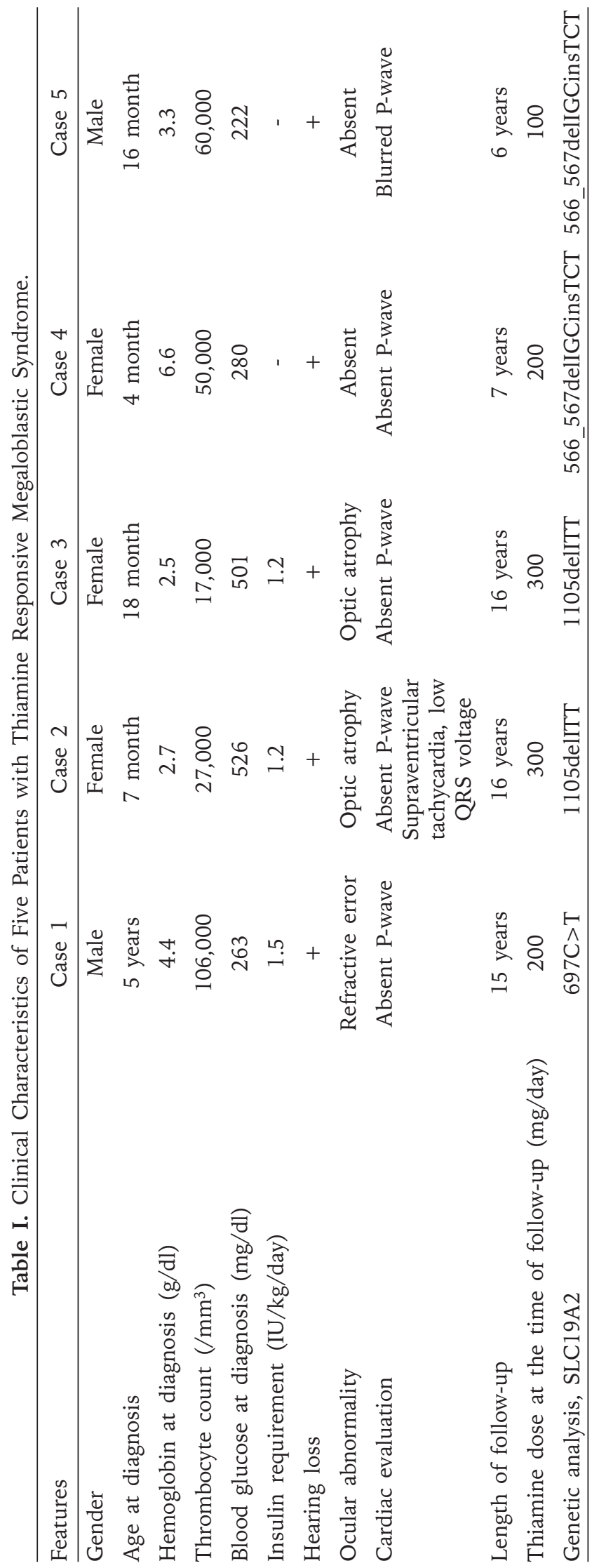




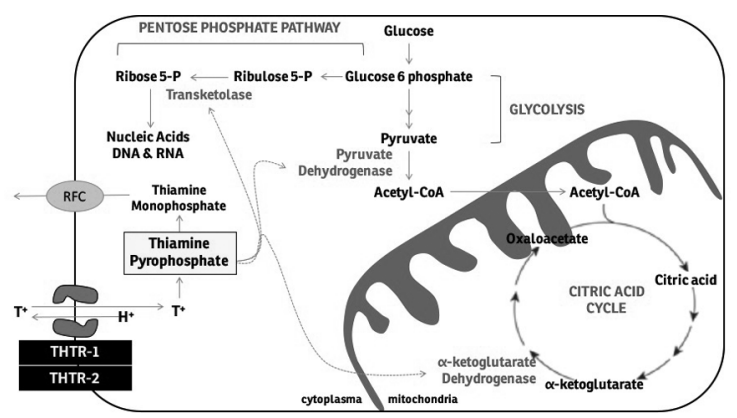

Fig. 1. Thiamine is transported into cells by THTR 1 and/or THTR 2. Thiamine pyrophosphate activate alpha ketoglutarate dehydrogenase, pyruvate dehydrogenase, transketolase.

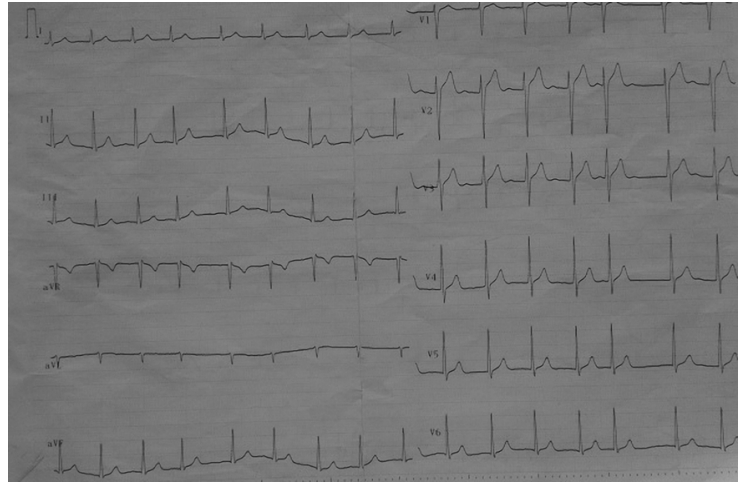

Fig. 3. Electrocardiography show absent $\mathrm{P}$ wave.

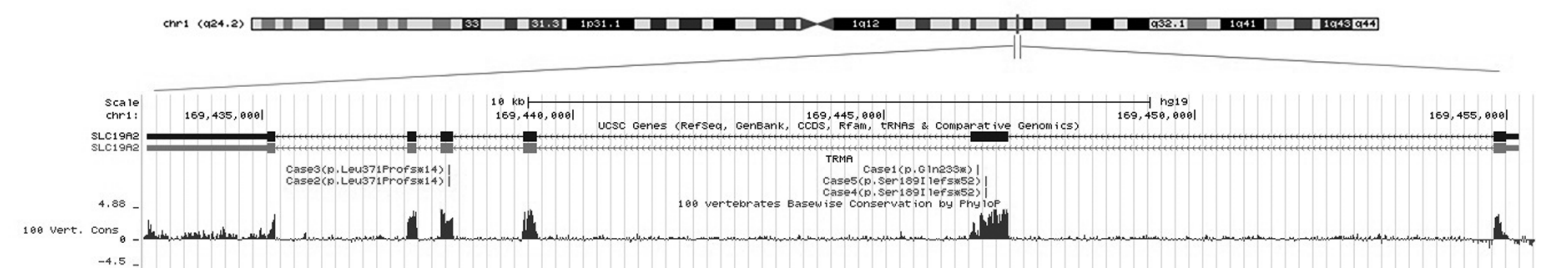

Fig. 2. A map of SLC19A2 gene showing mutations on protein in our patients.

2 and 3 were siblings. Molecular sequence analysis showed a homozygous c.697C $>$ T mutation in one patient, a homozygous c.1105delTT mutation in two patients and a homozygous two-base deletion and 3-base insertion c.566_567delGCinsTCT mutation in two patients (Fig. 2). All patients had macrocytic anemia, diabetes mellitus, and sensorineural deafness. Two patients who were siblings also had optic atrophy. During the follow-up of our patients with TRMAS, one of them developed supraventricular tachycardia as a cardiac manifestation during hospital stay for diabetic ketoacidosis after the discontinuation of thiamine therapy. All patients additionally showed the absence/flattening of $\mathrm{p}$ waves (Fig. 3 ), and one patient also had low voltage on 12-lead electrocardiography. None of our cases had congenital heart defects (Table I).

To date, supraventricular tachycardia has been reported in only 4 patients with TRMAS in the literature. ${ }^{7}$ In one of them, Ebstein anomaly accompanied the clinical picture whereas the other three cases had normal cardiac anatomy, as had our patients. Atrial fibrillation has been reported in four cases. ${ }^{7}$ Among these, two had normal cardiac anatomy, while two other had Ebstein anomaly. ${ }^{7}$ Absent or flattened p waves, first degree atrioventricular block, right bundle branch block, and wandering pacemaker have also been reported as rhythm disorders accompanying the syndrome. ${ }^{7}$ Only a few cases with congestive cardiomyopathy have been reported.7,8 Ebstein anomaly, secundum atrial septal defect, ventricular septal defect, endocardial cushion defect, dextrocardia, and Uhl anomaly are among cardiac defects previously reported in the literature. ${ }^{7}$ Arrhythmias are more common in subjects with TRMAS compared to general population. ${ }^{7}$

Discontinuation of thiamine therapy reportedly impairs glucose regulation and leads to diabetic ketoacidosis. Interrupting thiamine may similarly cause a tendency for supraventricular tachycardia episodes.

\section{REFERENCES}

1. Porter FS, Roger LE, Sidbury JB Jr. Thiamine-responsive megaloblastic anemia. J Pediatr 1969; 74: 494-504.

2. Boros LG, Steinkamp MP, Fleming JC, Lee WN, Cascante M, Neufeld EJ. Defective RNA ribose synthesis in fibroblasts from patients with thiamine-responsive megaloblastic anemia (TRMA). Blood 2003; 102: 35563561.

3. Akın L, Kurtoglu S, Kendirci M, Akın MA, Karakükçü $M$. Does early treatment prevent deafness in thiamineresponsive megaloblastic anemia syndrome? J Clin Res Pediatr Endocrinol 2011; 3: 36-39.

4. Ozdemir MA, Akcakus M, Kurtoglu S, Gunes T, Torun YA. TRMA syndrome (thiamine-responsive megaloblastic anemia): A case report and review of the literature. Pediatr Diabetes 2002; 3: 205-209. 
5. Kurtoglu S, Hatipoglu N, Keskin M, Kendirci M, Akcakus M. Thiamine withdrawal can lead to diabetic ketoacidosis in thiamine responsive megaloblastic anemia: Report of two siblings. J Pediatr Endocrinol Metab 2008; 21: 393-397.

6. Tubaş F, Akyıldız B, Özcan A, Kurtoğlu S, Akın L, Baykan A. Diyabetes mellituslu bir hastada tiamine yanıt veren supraventriküler taşikardi. Çocuk Sağlığı ve Hastalıkları Dergisi 2014; 57: 262-264.
7. Lorber A, Gazit AZ, Khoury A, Schwartz Y, Mandel $\mathrm{H}$. Cardiac manifestations in thiamine-responsive megaloblastic anemia syndrome. Pediatr Cardiol 2003; 24: 476-481.

8. Mandel H, Berant M, Hazani A, Naveh Y. Thiaminedependent beriberi in the "thiamine-responsive anemia syndrome”. N Engl J Med 1984; 311: 836-838. 